\title{
Quantifying right ventricular motion and strain using 3D cine DENSE MRI
}

\author{
Daniel A Auger ${ }^{1 *}$, Xiaodong Zhong ${ }^{2}$, Ernesta M Meintjes ${ }^{1}$, Frederick H Epstein ${ }^{3}$, Bruce S Spottiswoode ${ }^{1}$ \\ From 2011 SCMR/Euro CMR Joint Scientific Sessions \\ Nice, France. 3-6 February 2011
}

\section{Objective}

The purpose of this study is to quantify right ventricular (RV) motion and surface strain in normal volunteers using 3D cine DENSE MRI.

\section{Background}

The RV is difficult to image because of its thin wall, asymmetric geometry and complex motion. DENSE is a quantitative MRI technique for measuring myocardial displacement and strain at high spatial and temporal resolutions [1,2]. DENSE encodes tissue displacement directly into the image phase, allowing for the direct extraction of motion data at a pixel resolution. A free-breathing navigator-gated spiral 3D cine DENSE sequence was recently developed [3], providing an MRI technique which is well suited to quantifying RV mechanics.

\section{Methods}

Whole heart 3D cine DENSE data were acquired from two normal volunteers, after informed consent was obtained and in accordance with protocols approved by the University of Virginia institutional review board. The endocardial and epicardial contours were manually delineated to identify the myocardium from surrounding anatomical structures. A 3D spatiotemporal phase unwrapping algorithm was used to remove phase aliasing [4], and 3D Lagrangian displacement fields were derived for all cardiac phases. Midline contours were calculated from the epicardial and endocardial contours, and tissue tracking seed points were defined at pixel spaced intervals. A 3D tracking algorithm was implemented as a direct extension of the 2D tracking algorithm presented in [4], producing midline motion trajectories from which strain was calculated. Tangential 1D strain was calculated in the longitudinal and circumferential cardiac directions. Strain time curves are computed representing the free wall of the RV.

\section{Results}

Figure 1 illustrates the RV free wall mean tangential 1D strain time curves for approximately $3 / 4$ of the cardiac cycle over the apical-mid section of the heart for one

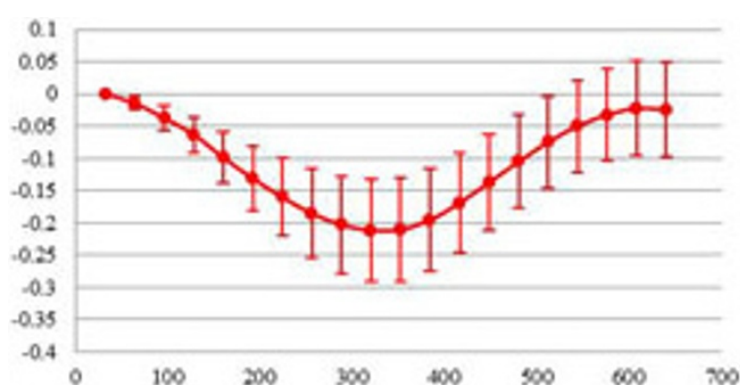

(a)

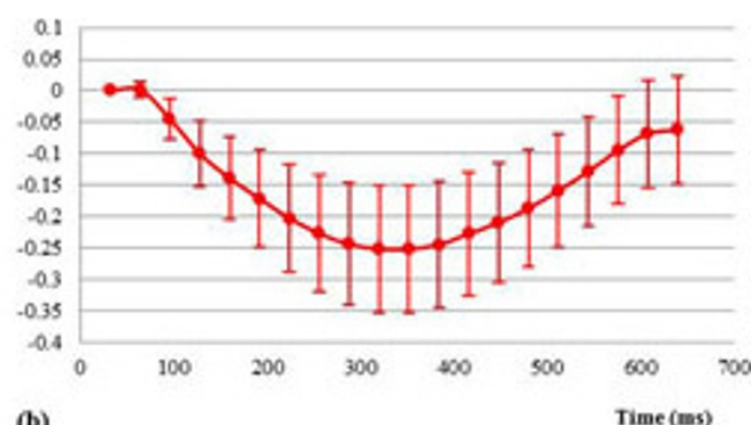

(b)

Figure 1 Data shown as mean \pm one standard deviation. (a) Circumferential and (b) Longitudinal strain.

'University of Cape Town, Cape Town, South Africa

Full list of author information is available at the end of the article

(c) 2011 Auger et al; licensee BioMed Central Ltd. This is an open access article distributed under the terms of the Creative Commons 
volunteer. Results show measurements ranging between -0.1 and -0.25 , and further illustrate a greater displacement in the longitudinal direction. Results compare favorably with studies using myocardial tagging and DENSE [5,6].

\section{Conclusion}

This work presents 3D motion tracking and strain quantification of the RV at a previously unattainable spatial resolution.

\section{Author details}

${ }^{1}$ University of Cape Town, Cape Town, South Africa. ${ }^{2}$ MR R\&D Collaborations, Siemens Medical Solutions, Atlanta, GA, USA. ${ }^{3}$ University of Virginia,

Charlottesville, VA, USA.

Published: 2 February 2011

\section{References}

1. Aletras, et al: Journal of Magnetic Resonance 1999, 137:247-252.

2. Kim, et al: Radiology 2004, 230(3):862-871.

3. Zhong, et al: Magnetic Rresonance in Medicine 2010, 64:1089-1097.

4. Spottiswoode, et al: IEEE Transactions on Medical Imaging 2007, 26(1):15-30.

5. Haber, et al: AJP - Heart 2005, 289:1826-1833.

6. Wen, et al: Radiology 2008, 246(1):229.

doi:10.1186/1532-429X-13-S1-M3

Cite this article as: Auger et al:: Quantifying right ventricular motion and strain using 3D cine DENSE MRI. Journal of Cardiovascular Magnetic Resonance 2011 13(Suppl 1):M3.
Submit your next manuscript to BioMed Central and take full advantage of:

- Convenient online submission

- Thorough peer review

- No space constraints or color figure charges

- Immediate publication on acceptance

- Inclusion in PubMed, CAS, Scopus and Google Scholar

- Research which is freely available for redistribution

Submit your manuscript at www.biomedcentral.com/submit
C Biomed Central 